(2) Open Access Full Text Article

\title{
Pharmacodynamic testing and new validated HPLC method to assess the interchangeability between multi-source orlistat capsules
}

This article was published in the following Dove Press journal:

Drug Design, Development and Therapy

Number of times this article has been viewed

\author{
Abdel Naser Zaid' \\ Nihal Zohud' \\ Bushra E'layan' \\ Tasneem Aburadi' \\ Nidal Jaradat ${ }^{\prime}$ \\ lyad $\mathrm{Ali}^{2}$ \\ Fatima Hussein' \\ Mashhour Ghanem ${ }^{3}$ \\ Aiman Qaddomi ${ }^{3}$ \\ Yara Abu Zaaror ${ }^{4}$ \\ 'Department of Pharmacy, \\ ${ }^{2}$ Department of Biomedical \\ Sciences, Faculty of Medicine and \\ Health Sciences, An-Najah National \\ University, Nablus, ${ }^{3}$ Department \\ of Regulatory, Pharmacare PLC, \\ ${ }^{4}$ Department of Research and \\ Development Pharmacare PLC, \\ Ramallah, Palestine
}

Background: Orlistat is an irreversible inhibitor of the lipase enzyme that prevents trigylcerides from being digested, thereby inhibiting triglyceride hydrolysis and absorption. The resultant reduced calorie uptake enables a positive effect on weight control. Systemic absorption of the drug is, therefore, not necessary for its mode of action. An alternative in vitro study (pharmacodynamic) has been introduced for this drug, as in vivo bioavailability studies are irrelevant with regard to the achievement of the product's intended purposes.

Objectives: To develop a new validated high-performance liquid chromatography (HPLC) method for the analysis of orlistat and to assess the potency and equivalence of three orlistat formulations using the pharmacodynamic method as a surrogate indicator of pharmaceutical interchangeability.

Methods: A new HPLC method was developed for the analysis and for the dissolution studies of orlistat in capsules. Pancreatic lipase activity was measured for three different capsule products: Orlislim ${ }^{\circledR}$, Slimcare ${ }^{\circledR}$, and Xenical ${ }^{\circledR}$, G1, G2, and the brand, respectively. Porcine pancreatic lipase and p-nitrophenyl butyrate (PNPB) were placed in a $\mathrm{pH} 7.4$ reaction buffer at $37^{\circ} \mathrm{C}$, and substrate hydrolysis was monitored by measuring absorbance changes at $410 \mathrm{~nm}$; this was repeated on six capsules of each product. The inhibition was expressed by the concentration of product, which inhibited $50 \%$ of the activity of pancreatic lipase $\left(\mathrm{IC}_{50}\right)$.

Results: The new analytical method was suitable for orlistat analysis. Values of $\mathrm{IC}_{50}$ from regression lines and equations were $6.14,8.43$, and $7.80 \mu \mathrm{g} / \mathrm{mL}$ for $\operatorname{Orlislim}^{\circledR}$, Xenical $^{\circledR}$, and Slimcare ${ }^{\circledR}$, respectively.

Conclusion: Pharmacodynamic studies of lipase inhibition could be used to support in vitro dissolution, which demonstrates interchangeability between generic and branded orlistat capsules. Moreover, it could be suggested as an alternative tool to bioequivalence studies for orlistat oral products.

Keywords: Orlistat, therapeutic equivalence, validation, pancreatic lipase

\section{Introduction}

Obesity is a chronic condition that is associated with significant morbidity and mortality. Globally, over 300 million individuals are obese, and an additional 800 million are overweight. ${ }^{1}$ In the United States, Eastern Mediterranean, and Pacific Islands, this prevalence ranges from approximately $30 \%$ to over $70 \%{ }^{2}$

Obesity has reached epidemic proportions and is becoming a public health concern of the first order. ${ }^{3}$ It affects approximately $23 \%$ of teenagers of southern European countries and is continuously increasing in many developing countries. ${ }^{4,5}$ 
The essence of obesity management is based on specific behavioral therapies, aiming to change eating habits and raise energy expenditure. Nutritional counseling aimed at lowering the intake of calories, particularly fat, with increased, daily, physical activities is highly recommended. Pharmacological management is seen as an additional tool to this basic therapy. ${ }^{6}$ Therapeutic treatment is indicated when the body mass index (BMI) is over $30 \mathrm{~kg} / \mathrm{m}^{2}$, when morbidities are associated with being overweight (BMI over $25 \mathrm{~kg} / \mathrm{m}^{2}$ ), when behavioral changes such as dieting and physical activities have been confirmed and proven to be ineffective. ${ }^{7,8}$

Orlistat belongs to a group of anti-obesity agents known as lipase inhibitors, which are designed for the long-term management of obesity and related comorbidities. Orlistat decreases the absorption of dietary fat as it has independent pharmacological lipid-lowering effects. ${ }^{9}$ It also improves insulin sensitivity ${ }^{10}$ and reduces body fat ${ }^{11}$ and serum leptin levels. ${ }^{12}$ Orlistat is a semisynthetic derivative of lipstatin, it is a potent and selective natural inhibitor of gastric and pancreatic lipases, which play an important role in the digestion of dietary fat. ${ }^{13}$ Chemically, orlistat is (S)-2formylamino-4-methyl-pentanoic acid (S)-1-[[(2S, 3S)-3hexyl-4-oxo-2-oxetanyl] methyl]-dodecyl ester (Figure 1). It is highly lipophilic and practically insoluble in water with no $\mathrm{pK}_{\mathrm{a}}$ value within a physiological $\mathrm{pH}$ range. ${ }^{14}$ The oral absorption of orlistat is very low, less than $1 \%$ of the administered dose, with no evidence of accumulation after long-term administration and it is rapidly eliminated and excreted primarily in the feces. ${ }^{15}$ Excretion via bile produces two metabolites. These metabolites, M1 and M3, have 2- and 3-hour half-lives, respectively, and they do not have any pharmacological effects. ${ }^{16}$

When administered along with fat-containing foods, orlistat partially inhibits hydrolysis of triglycerides. Therefore, it decreases the subsequent absorption of monoacyl

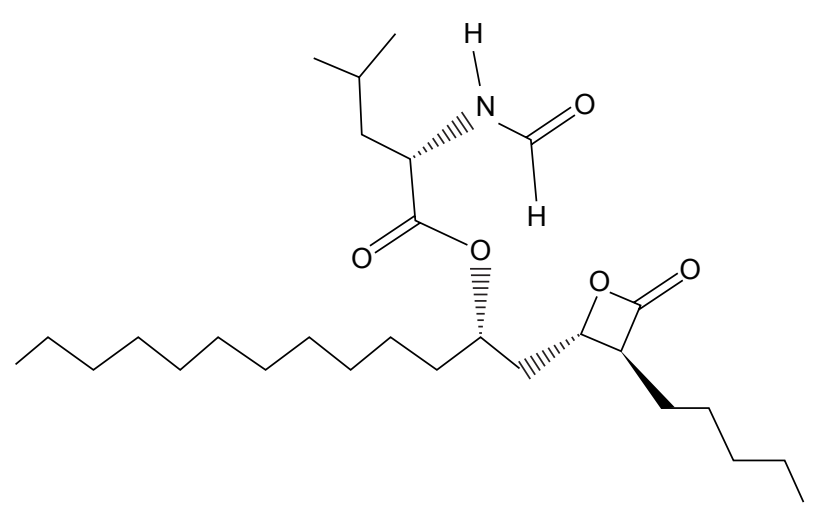

Figure I Chemical structure of orlistat. glycerides and free fatty acids. This action can be measured using a 24-hour fecal fat excretion as a representative pharmacodynamic parameter. It exerts its effect within the gastrointestinal tract (GIT). At therapeutic doses (120 mg three times daily with main meals) administered in conjunction with a well-balanced diet, the inhibition of fat absorption (approximately $30 \%$ of ingested dietary fat) leads to an additional caloric deficit of roughly 200 calories. ${ }^{13}$

The in vivo bioavailability studies of drugs are the most commonly used practical measure of the safety and effectiveness of any new drug. With regard to the new generic product, bioequivalence (BE) studies are the standard approved tool for proving a drug's safety and effectiveness. BE studies are usually done by comparing the drug's pharmacokinetic parameters with the original brand under the same study conditions. ${ }^{17}$ However, these studies may be considered unnecessary for drugs that have been classified under classes I and III of the biopharmaceutical classification system (BCS).${ }^{18}$ In certain circumstances, BE studies may not be demonstrable using drug concentrations, especially when the drug acts locally and has very limited intestinal absorption. Therefore, pharmacodynamic or clinical endpoints may be required as an alternative tool to improve its interchangeability with the original brand. ${ }^{19}$ In this circumstance, orlistat is intended for local action in the GIT, its absorption is negligible at the recommended therapeutic schedule, and its metabolite is not detectable in plasma (Zhi et $\mathrm{al}^{15}$ ). Accordingly, BE studies based on a comparison of pharmacokinetic parameters become insignificant. Therefore, the demonstration of efficacy and safety of a new generic orlistat formulation is becoming a true challenge for both pharmaceutical firms as well as regulatory bodies. The US Food and Drug Administration (FDA) reported a special guidance based on the pharmacodynamic estimation of orlistat. These guidelines involve the estimation of the percentage of fecal fat excretion over a 24-hour period. ${ }^{20}$ In this study, recruiting volunteers with a consistent diet, accurate fecal collection, and adequate fecal sample measurement represent a serious obstacle for the conduct of this test. Therefore, this guidance is nonbinding and only reflects the current thinking of the FDA on this topic, leaving an open door toward the use of alternative approaches, on condition that these approaches satisfy the requirements of the registration of an Abbreviated New Drug Application (ANDA). ${ }^{20}$

Accordingly, simpler and suitably designed relevant in vitro tests might be a reasonable way forward to establish $\mathrm{BE}$ for multisource orlistat formulations.

Therefore, in vitro testing based on similarity $\left(f_{2}\right)$ and non-similarity $\left(f_{1}\right)$ factors may be suggested as a surrogate for 
BE studies. However, this kind of study requires that $f_{2}$ and $f_{1}$ factors must be conducted at three different $\mathrm{pHs}$ as per the International Council for Harmonization ( $\mathrm{ICH}$ ) guidelines, and the results must be higher than 50 and less than 15 , respectively. This study aimed to investigate the effectiveness of $f_{2}$ and $f_{1}$, as a surrogate for the $\mathrm{BE}$ studies of orlistat capsules.

\section{Materials and methods Materials}

Three orlistat capsule formulations - one branded and two generic - were available in the Palestinian market and were purchased from a community pharmacy. The generic Orlislim $^{\circledR}$ (G1; $120 \mathrm{mg} /$ capsule) was produced by Birzeit Pharmaceuticals (Ramallah-Palestine). The brand Xenical ${ }^{\circledR}$ (120 mg/capsule) was manufactured by Roche. The second generic Slimcare ${ }^{\circledR}$ (G2; $120 \mathrm{mg}$ /capsule) was manufactured by Pharmacare PLC (Ramallah-Palestine). Dimethyl sulfoxide acetonitrile, p-nitrophenyl butyrate (PNPB), and Tris- $\mathrm{HCl}$ buffer were purchased from Sigma-Aldrich labrchemikalien $\mathrm{GmbH}$, (Germany) whereas porcine pancreatic lipase type II was obtained from Sigma (USA).

\section{Instruments}

Study instruments included a water-bath shaker, Radwag electrical balance, Jenway 7315 spectrophotometer (Bibby Scientific Ltd., Stone, UK), and an MRC ultrasonic cleaner (model: DC-200H).

\section{Methods}

\section{Assay and chromatographic conditions}

The amount of orlistat in the obtained capsule was assessed using the HPLC analytical method according to a new validated analytical method reported in the validation section. The HPLC experimental conditions were optimized on the HPLC instrument, provided with octadecyl silane $\mathrm{C}_{18}$ chemically bonded column $(150 \times 3.9 \mathrm{~mm}$ i.d., $5 \mu \mathrm{m}$ particles $)$. The optimum mobile phase was prepared by mixing 10 volumes of $0.1 \%$ orthophosphoric acid and 90 volumes of acetonitrile. The mobile phase was filtered using $0.45 \mu \mathrm{m}$ microporous filter and was degassed by sonication prior to use. A wavelength of $205 \mathrm{~nm}$ was selected and a flow rate of $1.0 \mathrm{~mL} /$ minute was used, with an injection volume of $25 \mu \mathrm{L}$. The peak quantification was obtained by comparing sample and standard peak area ratios as a function of concentration.

\section{Analytical validation}

The method was validated in accordance with the $\mathrm{ICH}$ guidelines. ${ }^{21}$ Parameters such as system suitability, selectivity, linearity, range, accuracy (recovery), and precision (repeatability) were all validated. The method was found to be valid, as shown from the results in Table 1. Validation of this analytical procedure was done using three trials of the product and one trial of the placebo product, all of which were prepared in the same laboratory, under the same conditions, and using the same excipients (microcrystalline cellulose $\mathrm{pH} 101$, sodium starch glycolate, polyplasdone, sodium lauryl sulfate, talc, and polyvinylpyrrolidone K-30). The purpose of this study was to establish confidence that the orlistat capsule assay method used was effective and reproducible according to the validation parameters that have been mentioned earlier. The dissolution test method for the orlistat capsule, based on the assay test method, was also validated.

\section{Standard solution}

To obtain a solution with a concentration of $0.12 \mathrm{mg} / \mathrm{mL}$, $12 \mathrm{mg}$ USP orlistat reference standard (RS) was placed in a $100 \mathrm{~mL}$ volumetric flask to which $80 \mathrm{~mL}$ methanol was added; the mixture was stirred and sonicated to dissolve the drug, and the solution was diluted to volume using methanol. (The solution would be stable for 1 week at $4^{\circ} \mathrm{C}$.)

\section{Sample preparation}

For sample preparation, $5 \mathrm{~mL}$ of the reconstituted suspension was transferred to a $100 \mathrm{~mL}$ volumetric flask, to which $75 \mathrm{~mL}$

Table I Summary results of the validation of assay of orlistat capsule

\begin{tabular}{lll}
\hline Parameter & Statistical measurement & Results \\
\hline Specificity & Not applied & No interference between \\
& & the orlistat peak and any \\
other peaks was observed & 99.5 \\
Accuracy & For $60 \%$ & 98.8 \\
& For 100\% & 98.9 \\
the active material peak & $98.00-102.00$ \\
Linearity & For I40\% & 0.9992 \\
Precision & Correlation coefficient & 0.39 \\
\hline
\end{tabular}

Abbreviation: RSD, relative standard deviation. 
diluent was then added. The mixture was shaken and sonicated for 30 minutes. The solution thus obtained was adjusted to volume using the same diluent. Thereafter, $5 \mathrm{~mL}$ of the supernatant were transferred to a $50 \mathrm{~mL}$ volumetric flask and diluted to the final volume using the mobile phase. A portion of this solution was filtered using a nylon filter with porosity equal to or less than $0.45 \mu \mathrm{m}$. The first $10 \mathrm{~mL}$ were rejected and the remaining portion of the filtrate was used for assay preparation.

Using ultrasound, the combined content of 20 capsules containing $120 \mathrm{mg}$ orlistat was mixed, $80 \mathrm{~mL}$ methanol was added, and the mixture was sonicated for 15 minutes. After cooling, sufficient methanol was added to produce $100 \mathrm{~mL}$ final volume, which was filtered through a $0.45 \mu \mathrm{m}$ membrane filter; $5.0 \mathrm{~mL}$ of the filtrate was transferred to a $50 \mathrm{~mL}$ volumetric flask, and the volume was adjusted to the mark using methanol.

\section{System suitability}

Test parameters were determined by injecting $25.0 \mu \mathrm{L}$ orlistat standard solution six times, with a final concentration of $120.0 \mu \mathrm{g} / \mathrm{mL}$ orlistat. According to the chromatograms, parameters such as injection precision for standard solution, tailing factor for standard solution, and theoretical plates for standard solution were calculated, as reported in Table 2.

\section{Dissolution study}

An in vitro dissolution study was conducted according to the reported FDA dissolution method for orlistat capsule. ${ }^{22}$ To carry out this test, a dissolution apparatus, USP (type II) at a paddle speed of 75 rounds per minute, was used. The dissolution medium was $900 \mathrm{~mL} \mathrm{3 \%} \mathrm{sodium} \mathrm{lauryl}$ sulfate in $0.5 \%$ sodium chloride at $\mathrm{pH} 6.0 \pm 0.05$. This dissolution apparatus was kept at $37^{\circ} \mathrm{C}$ for the entire study duration. One capsule was placed in each paddle. Samples $(10 \mathrm{~mL})$ were taken at the desired time, and placed in the same volume of the blank.

Table 2 Orlistat release profile from Orlislim $^{\circledR}(\mathrm{GI})$, Slimcare ${ }^{\circledR}$ (G2), and the RLD $\left(\right.$ Xenical $\left.^{\circledR}\right)$ at $\mathrm{pH} 6.0$

\begin{tabular}{llll}
\hline $\begin{array}{l}\text { Time } \\
\text { (minutes) }\end{array}$ & $\begin{array}{l}\text { Brand } \\
\text { average \% } \\
\text { release } \pm \text { SD }\end{array}$ & $\begin{array}{l}\text { G2 } \\
\text { average \% } \\
\text { release } \pm \text { SD }\end{array}$ & $\begin{array}{l}\text { G I } \\
\text { average \% } \\
\text { release } \pm \text { SD }\end{array}$ \\
\hline 0 & 0 & 0 & 0 \\
5 & $52.85 \pm 1.68$ & $63.82 \pm 1.80$ & $72.37 \pm 3.88$ \\
15 & $96.37 \pm 2.33$ & $94.55 \pm 1.62$ & $98.50 \pm 1.10$ \\
25 & $105.60 \pm 1.49$ & $102.72 \pm 0.83$ & $100.35 \pm 1.28$ \\
35 & $108.78 \pm 1.46$ & $102.83 \pm 1.42$ & $101.12 \pm 1.97$ \\
45 & $103.95 \pm 0.92$ & $101.20 \pm 0.75$ & $100.72 \pm 1.63$ \\
\hline
\end{tabular}

Abbreviation: RLD, reference listed drug.

\section{Related substances Preparation of the test solution}

For the test solution, $100 \mathrm{mg}$ crushed orlistat pellets were accurately weighed and transferred to a $50 \mathrm{~mL}$ volumetric flask, dissolved in the mobile phase, and diluted to the desired mark with the same mobile phase.

\section{Preparation of the reference solution}

For the reference solution, $1.0 \mathrm{~mL}$ test solution was accurately transferred into a $10 \mathrm{~mL}$ volumetric flask, diluted to the volume using the mobile phase, and mixed well to ensure homogenization.

\section{Chromatographic procedure}

The mobile phase was composed of a mixture of 85 volumes of methanol and 15 volumes of water. The stationary phase was composed of a stainless steel column $(125 \times 4.0 \mathrm{~mm})$ packed with octylsilane chemically bonded to porous silica particles for chromatography $(5 \mu \mathrm{m})$. The flow rate was set at $1 \mathrm{~mL} /$ minute and the wavelength was set at $210 \mathrm{~nm}$.

To assess the related substances, $20 \mu \mathrm{L}$ reference solution and test solution were injected and the related substances were calculated using the following formula:

$$
\begin{gathered}
\text { For any individual impurity }=A i \times C s t \times 100 \% \\
\qquad A=C s a
\end{gathered}
$$

For total impurities $=A t \times C s t \times 100 \%$

$$
A=C s a
$$

where, $A i$ stands for individual impurity peak area of test solution, At stands for total impurities peak area of test solution, $A$ stands for the major peak area of the reference solution, Cst means concentration of orlistat in the standard preparation $(\mathrm{mg} / \mathrm{mL})$, and Csa stands for concentration of orlistat in the sample preparation $(\mathrm{mg} / \mathrm{mL})$.

\section{Pharmacodynamic study} Preparation of test $(T)$ and reference $(R)$ working stock solutions

It is worth mentioning that all samples, including test and placebo, were treated under the same conditions. In fact, both test and reference products were kept in the same conditions and treated in the same way in all steps of the experiment. Precisely, six stock test solutions $(1 \mathrm{mg} / \mathrm{mL})$ of each product (G1, G2, and the brand) were prepared by dispersing the content of each capsule in a $100 \mathrm{~mL}$ volumetric flask. Thereafter, the dispersions were shaken for 1 hour, and then 
sonicated to ensure homogeneity and complete dissolution of the granules in the solvent. Then, nine serial dilutions $(10,20,30,50,80,100,200,300$, and $500 \mu \mathrm{g} / \mathrm{mL})$ were prepared using the same buffer. Further, a $1 \mathrm{mg} / \mathrm{mL}$ stock solution of porcine pancreatic lipase enzyme was prepared immediately before use in $10 \%$ DMSO solution, followed by the addition of $5 \mathrm{~mL}$ Tris- $\mathrm{HCl}$ stock solution and $0.5 \mathrm{~mL}$ pancreatic lipase. A test tube containing $5 \mathrm{~mL}$ Tris- $\mathrm{HCl}$ and $0.5 \mathrm{~mL}$ pancreatic lipase enzyme without inhibitor was used as a blank. This procedure was repeated for each of the six capsules for each drug product. Then, nine test tubes with the blank were incubated at $37^{\circ} \mathrm{C}$ for 15 minutes. To all tubes (including the blank), $0.5 \mathrm{~mL}$ p-nitrophenyl butyrate (PNPB; which was prepared by dissolving $20.9 \mathrm{mg}$ in $2 \mathrm{~mL}$ acetonitrile) was added and incubated for 30 minutes. The effect of all prepared solutions of test and reference products on porcine pancreatic lipase activity were evaluated.

\section{Measurement of pancreatic lipase activity}

In this study, to investigate pancreatic lipase activity, a known procedure was adopted that utilizes p-nitrophenyl esters, such as PNPB, as reported in Figure 2. The release of p-nitrophenol is measured spectrophotometrically at $410 \mathrm{~nm}$ wavelength so that absorbance of each test tube for the six capsules of the studied products (generic and brand) was measured using an ultraviolet-visible spectrophotometer. ${ }^{23}$

\section{Calculating pancreatic lipase inhibition}

Pancreatic lipase inhibition is indicated by the hydrolysis of PNBP to p-nitrophenol. The extent of lipase inhibition has a negative impact on the amount of p-nitrophenol released. In order to detect the amount of p-nitrophenol released, and accordingly the impact of the inhibitor, the blank absorption has to be subtracted (some p-nitrophenol may be released due to acidic media) from the total value according to the equation below, used for calculating the pure inhibitory activity. ${ }^{24}$
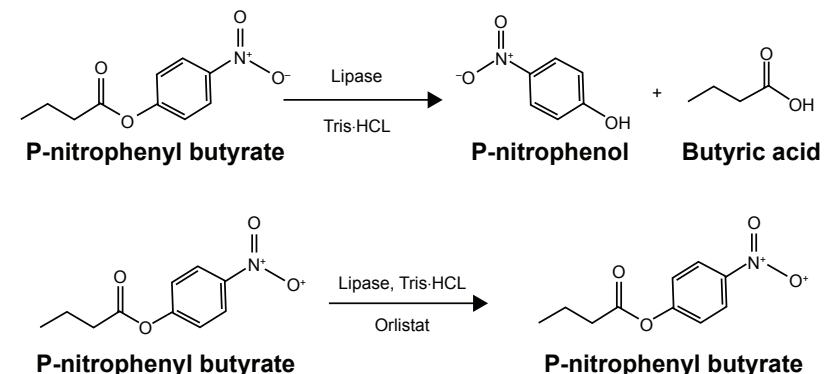

Figure 2 Hydrolysis of p-nitrophenyl butyrate (PNPB) with and without orlistat.
Table 3 Degree of inhibition (\%) \pm SD of the $\operatorname{Orlislim}^{\circledR}(\mathrm{GI})$, Slimcare ${ }^{\circledR}(\mathrm{G} 2)$, and the RLD (Xenical $\left.{ }^{\circledR}\right)$

\begin{tabular}{llll}
\hline $\begin{array}{l}\text { Theoretical } \\
\text { concentration } \mu \mathrm{g} / \mathrm{mL}\end{array}$ & \multicolumn{4}{l}{ Test products } \\
\cline { 2 - 4 } & \multicolumn{3}{l}{ Degree of inhibition (\%) \pm SD } \\
\cline { 2 - 4 } & GI & RLD & G2 \\
\hline 0 & 0 & 0 & 0 \\
10 & $64.29 \pm 3.3$ & $73.03 \pm 1.08$ & $66.67 \pm 4.39$ \\
20 & $74.36 \pm 0.21$ & $78.57 \pm 1.06$ & $73.68 \pm 2.17$ \\
30 & $75.00 \pm 3.72$ & $83.13 \pm 0.42$ & $78.72 \pm 1.46$ \\
50 & $80.00 \pm 3.30$ & $85.97 \pm 0.78$ & $81.48 \pm 1.46$ \\
80 & $86.49 \pm 0.41$ & $87.56 \pm 0.60$ & $84.85 \pm 1.41$ \\
100 & $87.65 \pm 0.48$ & $88.54 \pm 0.32$ & $86.84 \pm 0.60$ \\
200 & $89.13 \pm 0.21$ & $89.13 \pm 0.18$ & $87.95 \pm 0.61$ \\
300 & $89.90 \pm 0.31$ & $89.83 \pm 0.34$ & $89.01 \pm 0.26$ \\
500 & $92.59 \pm 0.26$ & $91.85 \pm 0.29$ & $89.47 \pm 0.19$ \\
\hline
\end{tabular}

Abbreviation: RLD, reference listed drug.

$$
\% \text { of enzyme inhibition }=\left[1-\frac{S}{B}\right] \cdot 100 \%
$$

where, $S$ refers to the absorbance of the sample; $B$ refers to the blank absorbance.

After detecting absorbance, the average of six capsules \pm standard deviation (SD) has been considered for each drug product at each concentration to produce a single reliable absorbance value, as reported in Table 3.

$\mathrm{The}_{\mathrm{IC}}$ of the test samples were obtained from the leastsquares regression line of the plots of the logarithm of the sample concentration versus the pancreatic lipase inhibition (\%), and the SDs of each trial were taken in consideration, which gives a clue as to how the data were distributed (Figure 3; Table 3).

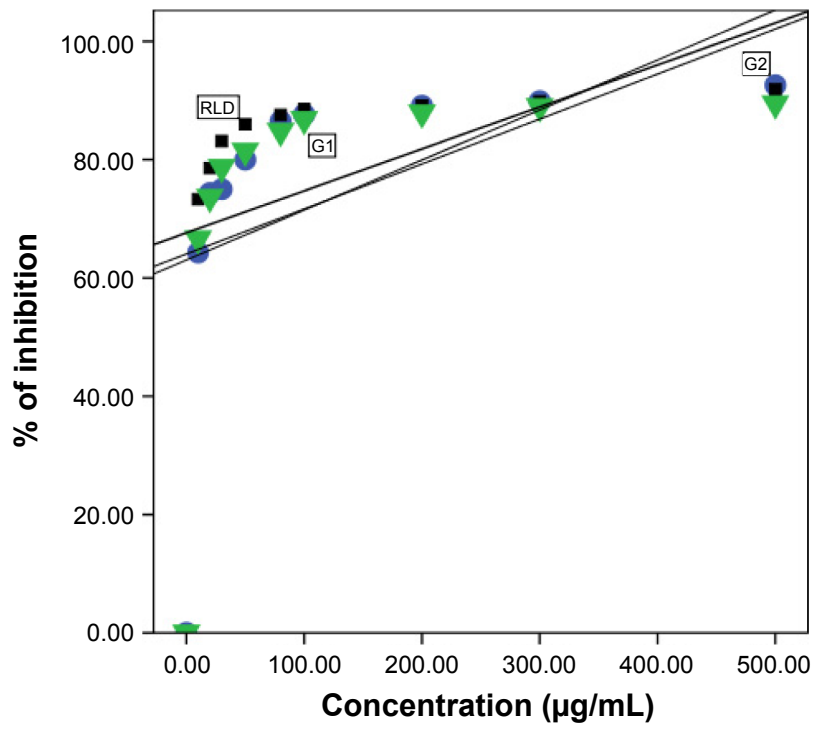

Figure 3 The pancreatic lipase inhibitory effect of both the Orlislim ${ }^{\circledast}(\mathrm{GI})$, Slimcare ${ }^{\circledast}$ (G2), and the RLD (Xenical ${ }^{\circledR}$ ).

Abbreviation: RLD, reference listed drug. 


\section{Results}

\section{Results of analytical validation}

The analytical method used in this study was found to be valid for the assay and dissolution of orlistat in the capsules because all validation parameters were within acceptable levels, as reported in Table 1. Moreover, parameters of system suitability were assessed, and were found to be within the accepted criteria because the injection precision and tailing factors for standard solution were less than $2 \%$, as summarized in Table 4 . The related substances test was carried out according to the validated method of analysis. ${ }^{25}$ Metabolites of orlistat was not detected in vitro. All results were within the acceptable limit, as reported in Tables 1 and 4 .

As shown in Figure 4, the dissolution of orlistat capsules of both generic products showed a dissolution profile comparable with that of the original branded drug.

\section{Results of dissolution under FDA conditions}

With regard to the in vitro dissolution, both generic products showed dissolution profiles strongly comparable with the original brand when tested at the recommended $\mathrm{pH}$ media parameters (FDA conditions). In fact, all products released more than $85 \%$ of their active ingredient within 15 minutes, as shown in Table 2 and Figure 4. Thus, there was no need for the calculation of similarity and dissimilarity factors as indicated by the ICH guidelines. On the other hand, the dissolution of orlistat from all mentioned products was less than $6 \%$, and close to $1 \%$ when conducted at $\mathrm{pH} 6.8,4.5$, and acidic $\mathrm{pH}(0.1 \mathrm{~N} \mathrm{HCl}$ solution).

\section{Results of enzymatic inhibition}

Concerning pharmacodynamic analyses, all orlistat products available in the Palestinian pharmaceutical market were subjected to this study. The inhibitory effect of orlistat in the test and reference was dose dependent. Different solutions of the test and reference products were prepared in escalating doses, as shown in Table 3.

The values of $\mathrm{IC}_{50}$ for both products were calculated, and the degree of lipase inhibition was plotted (Figure 3). The degree of similarity with the studied product was estimated,

Table 4 Summary of system suitability for orlistat analysis

\begin{tabular}{lll}
\hline Parameter & Data & Limit \\
\hline Injection precision for standard solution & 0.14 & $<2.0 \%$ \\
Tailing factor for standard solution & 1.03 & $<2.0$ \\
Theoretical plates for standard solution & 4,370 & $>2,000$ \\
\hline
\end{tabular}

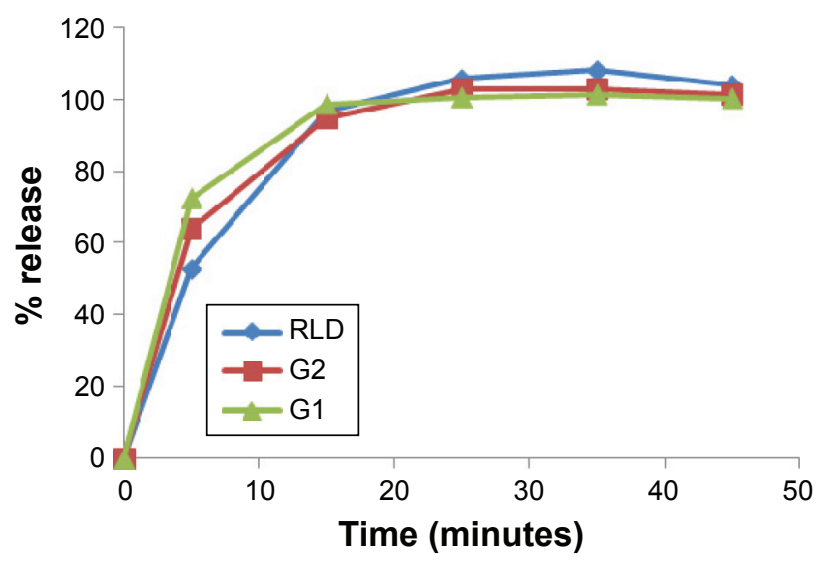

Figure 4 Orlistat in vitro release profile from $\operatorname{Orlislim}^{\circledast}(G I)$, Slimcare ${ }^{\circledR}(G 2)$, and the RLD $\left(\right.$ Xenical $\left.^{\circledR}\right)$.

Abbreviation: RLD, reference listed drug.

and the SDs were calculated, which showed how the data were distributed.

$\mathrm{The}_{\mathrm{IC}}$ value represents the concentration of the inhibitor at which $50 \%$ of the enzyme is inhibited, and it is generally used to express the effectiveness of enzyme inhibitors. It can be assessed by least-square regression of the linear segment of theoretical concentration versus the percentage of inhibition curves. ${ }^{26} \mathrm{We}$ used the values of $\mathrm{IC}_{50}$ from the regression lines and equations, which were $6.14,8.43$, and $7.80 \mu \mathrm{g} / \mathrm{mL}$ for Xenical ${ }^{\circledR}$, Slimcare $^{\circledR}$, and Orlislim ${ }^{\circledR}$, respectively. These values are considered similar, and this is clear as the values of degree of inhibition are very close to each other (Table 3). Statistical analysis (using IBM SPSS 19) of these results have revealed that there is no significant difference between the three regression equations of all test products $(p>0.1)$. In fact, despite the slower initial release of orlistat from the branded product, compared with G1 and G2 as shown in the release study, a faster inhibitory action at low concentration was shown by the branded product as compared with that of G1 and G2 (Figure 3).

\section{Discussion}

To assess the assay and to conduct a dissolution study on orlistat capsules, a validated HPLC method was developed according to the ICH guidelines by testing several validation parameters, such as: detection of wavelength, composition of mobile phase, optimum $\mathrm{pH}$, and the effect of slight variation of these parameters on the qualitative and quantitative analysis of orlistat. In fact, the method demonstrated excellent accuracy within the desired concentration range. The results clearly demonstrate the ruggedness of the developed method, and the results indicate that the testing of the sample on different days by different analysts do not affect the assay 
and its ability to accurately and precisely detect/quantify the active ingredients.

With regard to in vitro-in vivo correlation (IVIVC), it is used to predict similarity between generic and reference listed drug (RLD), which confirms generic interchangeability and therapeutic equivalence as well as safety, efficacy, and good quality. ${ }^{27}$ In vivo studies, in spite of being essential, may consume unnecessary time, money, and effort in addition to involving critical and sensitive ethical considerations (World Health Organization 2006).

Biowaiver, an alternative in vitro tool to predict drugproduct interchangeability, can be granted in some cases, as permitted by the FDA. In fact, the FDA allowed some products to be biowaived, which means that in vivo procedures are not an obligatory requirement such as for classes I and III drugs according to BCS. In addition, BE studies can be waived when the API does not produce measurable concentrations in an accessible biological fluid. Comparative clinical trials, as well as comparative pharmacodynamic studies, are further alternative tools to document equivalence in such circumstances. $^{28}$

Orlistat is a semisynthetic drug that was been approved in 1999 by the FDA. It is a hydrogenated form of a natural lipase inhibitor produced by Streptomyces toxytricini. ${ }^{16}$ Systemic absorption, after oral administration, of orlistat is less than $1 \% .{ }^{16}$ As orlistat acts locally and systemic absorption is unnoticeable, ${ }^{15}$ in vivo tests are extremely difficult to conduct because neither the drug nor its metabolite can be detected in the plasma. Therefore, stool analysis to assess the percentage of unabsorbed fat is the only in vivo method to evaluate the efficacy of the generic orlistat product. ${ }^{20}$

To the best of our knowledge, it would be very difficult to find a clinical research center that is suitable to conduct in vivo studies. Accordingly, many regulatory bodies including the Palestinian regulation body accept the in vitro analysis of this product. These studies include dissolution comparison between the generic and RLD, conducted in three different $\mathrm{pH}$ media $(1.2,4.5$, and 6.8$)$. Our in vitro release studies demonstrated the complete release of orlistat from the two generic and RLD products when conducted in FDA-recommended $\mathrm{pH}$ media, which contain $0.5 \%$ sodium lauryl sulfate. Unfortunately, these results were not sufficient to support interchangeability because release in media of other $\mathrm{pH}$, such as acidic and phosphate buffers, was almost negligible. In fact, these media do not contain sodium lauryl sulfate, which is a strong wetting and dissolving agent. Accordingly, these results may need further in vivo investigational studies to ensure interchangeability between G1,
G2, and RLD products. Recently, a pharmacodynamic study based on lipase inhibition emerged as a BE surrogate to prove clinical interchangeability between product formulations. ${ }^{23}$ However, in this study six orlistat capsules were simultaneously dispersed in the buffer media, which revealed a significant difference between products but could not explore any variation with regard to enzyme inhibition. Six stock solutions of each product were prepared by using six capsules of both generic and brand products for ensuring both reliability and to assess any intravariation in the same product (reference again).

As summarized in Table 3 and Figure 3, all products showed a comparable inhibitory effect at concentrations equal to or higher than $80 \mu \mathrm{g} / \mathrm{mL}$ orlistat ( $p$-value higher than 0.05$)$. This initial and non-significant discrepancy may be due to differences in the grade or ratios of excipients used in the various manufactured capsules (branded and generic) that may encourage the use of the pharmacodynamic test to support the conventional drug-release study as the in vitro tool for drug quality testing. In fact, this pharmacodynamic study was used as surrogate indicator of clinical interchangeability between generics and RLD. ${ }^{23}$

Accordingly, the in vitro dissolutions study, as recommended by the FDA, and pharmacodynamic testing could support each other by using them as a surrogate for orlistat BE studies.

\section{Conclusion}

The HPLC analytical method used was suitable for the qualitative and quantitative analysis of orlistat. The validation parameters were within the limits specified by the ICH guidelines. The generic products are interchangeable with the branded product, according to the FDA dissolutions method and the pharmacodynamic testing used. Both in vitro and enzyme inhibition tests support each other as a surrogate for orlistat BE studies, and even should be used in routine analysis to demonstrate the quality of these products. However, a comparison between in vitro pharmacodynamic studies and in vivo clinical or pharmacodynamic studies are lacking, which represents a limitation against the use of this important in vitro tool. Accordingly, future studies such as in vitro-in vivo correlation may be conducted to assess the effectiveness of this test.

\section{Acknowledgment}

The authors thank Linda Isa for technical support during this project, and Saja Darwish for assistance with language editing. 


\section{Disclosure}

Aiman Qaddomi and Yara Abu Zaaror are employees of Pharmacare PLC, the other authors have no conflicts of interest in this work.

\section{References}

1. Haslam DW, James WP. Obesity. Lancet. 2005;366(9492):1197-1209.

2. Flegal KM, Carroll MD, Ogden CL, Johnson CL. Prevalence and trends in obesity among US adults, 1999-2000. JAMA. 2002;288(14): $1723-1727$.

3. Musaiger AO, Al-Mannai M, Tayyem R, et al. Prevalence of overweight and obesity among adolescents in seven Arab countries: a cross-cultural study. J Obes. 2012;2012:981390.

4. García Díaz E, Folgueras TM. Systematic review of the clinical efficacy of sibutramine and orlistat in weight loss, quality of life and its adverse effects in obese adolescents. Nutr Hosp. 2011;26(3):451-457.

5. Wang Y, Monteiro C, Popkin BM. Trends of obesity and underweight in older children and adolescents in the United States, Brazil, China, and Russia. Am J Clin Nutr. 2002;75(6):971-977.

6. Prentice AM, Jebb SA. Obesity in Britain: gluttony or sloth? BMJ. 1995;311(7002):437-439.

7. WHO. Obesity: Preventing and Managing the Global Epidemic. Geneva: World Health Organization; 2000.

8. Guy-Grand B. Long term pharmacotherapy in the management of obesity. In Bjorntorp P, Rossner S, eds. From Theory to Practice: Obesity in Europe. London: John Libbey; 1989:311-318.

9. Hollander PA, Elbein SC, Hirsch IB, et al. Role of orlistat in the treatment of obese patients with type 2 diabetes. A 1-year randomized double-blind study. Diabetes Care. 1998;21(8):1288-1294.

10. Rosenfalck AM, Hendel H, Rasmussen MH, et al. Minor long-term changes in weight have beneficial effects on insulin sensitivity and beta-cell function in obese subjects. Diabetes Obes Metab. 2002;4(1): $19-28$.

11. Karhunen L, Franssila-Kallunki A, Rissanen P, et al. Effect of orlistat treatment on body composition and resting energy expenditure during a two-year weight-reduction programme in obese Finns. Int $J$ Obes Relat Metab Disord. 2000;24(12):1567-1572.

12. Rodrigues AM, Radominski RB, Suplicy Hde L, De Almeida SM, Niclewicz PA, Boguszewski CL. The cerebrospinal fluid/serum leptin ratio during pharmacological therapy for obesity. J Clin Endocrinol Metab. 2002;87(4):1621-1626.

13. Guerciolini R. Mode of action of orlistat. Int JObes Relat Metab Disord. 1997;21 (Suppl 3):S12-S23.

14. Taylor PW, Arnet I, Fischer A, Simpson IN. Pharmaceutical quality of nine generic orlistat products compared with Xenical(r). Obes Facts. 2010;3(4):231-237.
15. Zhi J, Melia AT, Eggers H, Joly R, Patel IH. Review of limited systemic absorption of orlistat, a lipase inhibitor, in healthy human volunteers. J Clin Pharmacol. 1995;35(11):1103-1108.

16. Al-Suwailem K, Al-Tamimi AS, Al-Omar MA, Al-Suhibani MS. Safety and mechanism of action of orlistat (tetrahydrolipstatin) as the first local antiobesity drug. J Appl Sci Res. 2006;2(4):205-208.

17. Chen ML, Shah V, Patnaik R, et al. Bioavailability and bioequivalence: an FDA regulatory overview. Pharml Res. 2001;18(12):1645-1650.

18. Gupta E, Barends DM, Yamashita E, et al. Review of global regulations concerning biowaivers for immediate release solid oral dosage forms. Eur J Pharm Sci. 2006;29(3-4):315-324.

19. European Medicines Agency. Committee for medicinal products for human use (CHMP) 2010. Available from: http://www.ema.europa. eu/docs/en_GB/document_library/Scientific_guideline/2010/01/ WC500070039.pdf. Accessed December 3, 2016.

20. Food and Drug Administration. Draft guidance on orlistat 2010. Available from: https://www.fda.gov/downloads/Drugs/Guidance ComplianceRegulatoryInformation/Guidances/UCM201268.pdf. Accessed March 27, 2017.

21. ICH. Validation of Analytical Procedures: Text and Methodology. USA: ICH Steering Committee; 2005.

22. FDA. Rosuvastatin tablet. 2015. Available from: http://www.accessdata.fda.gov/drugsatfda_docs/label/2010/021366s016lbl.pdf. Accessed June 28, 2016.

23. Bustanji Y, Mohammad M, Hudaib M, et al. Screening of some medicinal plants for their pancreatic lipase inhibitory potential. Jordan J Pharml Sci. 2011;4(2):81-88.

24. Dzomba P, Musekiwa C. Anti-obesity and antioxidant activity of dietary flavonoids from Dioscorea steriscus tubers. J Coast Life Med. 2014;2(6):465-470.

25. The International Council for Harmonisation. European pharmacopoeia, quality guidelines. 2016. Available from: http://www.ich.org/products/ guidelines/quality/article/quality-guidelines.html. Accessed March 27, 2017.

26. Mohammad M, Aiedeh KM, AlKhatib HS, et al. A comparative enzymatic inhibition assay as a surrogate indicator of pharmaceutical and potency equivalence of two orlistat formulations. Jordan J Pharml Sci. 2010;3(2):69-74.

27. World Health Organization. Multisource (generic) pharmaceutical products: guidelines on registration requirements to establish interchangeability. WHO Technical Report Series. 2006. Available from: http://apps.who.int/prequal/info_general/documents/trs937/ who_trs_937_annex7_eng.pdf. Accessed November 9, 2016.

28. World Health Organization. Proposal to waive in vivo bioequivalence requirements for WHO Model List of Essential Medicines immediaterelease, solid oral dosage forms. 2006. Available from: http://apps. who.int/prequal/info_general/documents/TRS937/WHO_TRS_937_ annex8_eng.pdf. Accessed November 9, 2016.
Drug Design, Development and Therapy

\section{Publish your work in this journal}

Drug Design, Development and Therapy is an international, peerreviewed open-access journal that spans the spectrum of drug design and development through to clinical applications. Clinical outcomes, patient safety, and programs for the development and effective, safe, and sustained use of medicines are the features of the journal, which

\section{Dovepress}

has also been accepted for indexing on PubMed Central. The manuscript management system is completely online and includes a very quick and fair peer-review system, which is all easy to use. Visit http://www.dovepress.com/testimonials.php to read real quotes from published authors. 